\title{
Aldehyde Dehydrogenase X, Mitochondrial
}

National Cancer Institute

\section{Source}

National Cancer Institute. Aldehyde Dehydrogenase X, Mitochondrial. NCI Thesaurus.

Code C97219.

Aldehyde dehydrogenase $X$, mitochondrial (517 aa, $\sim 57 \mathrm{kDa}$ ) is encoded by the human ALDH1B1 gene. This protein is involved in the metabolism of alcohol-derived acetaldehyde. 